\title{
In vitro digestion and stability assessment of $\beta$-lactoglobulin/riboflavin nanostructures
}

\author{
Daniel A. Madalena a , Óscar L. Ramos a, b, Ricardo N. Pereira ${ }^{\text {a, * }}$, Ana I. Bourbon ${ }^{\text {a }}$, \\ Ana C. Pinheiro ${ }^{a}$, F. Xavier Malcata ${ }^{b, c}$, José A. Teixeira ${ }^{a}$, António A. Vicente ${ }^{a}$ \\ ${ }^{a}$ CEB-Centre of Biological Engineering, University of Minho, 4710-057, Braga, Portugal \\ ${ }^{\mathrm{b}}$ LEPABE - Department of Chemical Engineering, Faculty of Engineering, University of Porto, Porto, Portugal \\ c Department of Chemical Engineering, Rua Dr Roberto Frias, P-4200-465 Porto, Portugal
}

\section{A R T I C L E I N F O}

\section{Article history:}

Received 24 September 2015

Received in revised form

9 February 2016

Accepted 13 February 2016

Available online 16 February 2016

\section{Keywords:}

Bio-based nanostructures

$\beta$-Lactoglobulin

Riboflavin

In vitro gastrointestinal system

Food simulant

\begin{abstract}
A B S T R A C T
$\beta$-Lactoglobulin ( $\beta$ - $\mathrm{Lg})$ is the major protein fraction of bovine whey serum and a primary gelling agent. $\beta$ Lg has a high nutritional value, is stable at low $\mathrm{pH}$ being highly resistant to proteolytic degradation in the stomach, besides, it has the ability of acting as an encapsulating agent. This study aims at assessing the ability of $\beta$-Lg nanostructures to associate a nutraceutical - i.e. riboflavin - and release it in a controlled manner throughout an in vitro gastrointestinal (GI) system. For this reason $\beta$-Lg nanostructures loaded with riboflavin were critically characterized in terms of their morphology (i.e. size, polydispersity, $\zeta-$ potential and shape) by dynamic light scattering (DLS) and transmission electron microscopy (TEM), and efficiency to associate to riboflavin through spectrofluorimetry. Furthermore, these nanocomplexes were evaluated in an in vitro GI model, simulating the physiological conditions. Stable $\beta$-Lg nanostructures were obtained at $\mathrm{pH} 6$, of spherical shape, characterized by particle size of $172 \pm 1 \mathrm{~nm}$, low polydispersity (i.e. PDI of $0.06 \pm 0.02$ ), $\zeta$-potential of $-32 \pm 3 \mathrm{mV}$ and association efficiency (AE) of $26 \pm 1 \%$. $\beta$ - $\mathrm{Lg}$ nanostructures showed to be stable upon their passage throughout stomach (i.e. particle size, PDI and $\zeta$ potential of $248 \pm 10 \mathrm{~nm}, 0.18 \pm 0.03$ and $18 \pm 3 \mathrm{mV}$, respectively). Concerning their passage throughout the intestine, such nanostructures were mostly degraded in the duodenum. Regarding riboflavin, a release of about $11 \%$ was observed after their passage through stomach, while $35 \%, 38 \%$ and $5 \%$ were the released percentages of the total riboflavin associated observed after passage through duodenum, jejunum and ileum, respectively. Hence, $\beta$-Lg nanostructures showed to be suitable carriers for riboflavin until the intestine, where their degradation occurs. $\beta$ - $\mathrm{Lg}$ also showed to be structurally stable, under food simulant conditions (yoghurt simulant, composed of $3 \%$ acetic acid), over 14 days, with a protective effect upon riboflavin activity, releasing it in a 7 day period.
\end{abstract}

() 2016 Elsevier Ltd. All rights reserved.

\section{Introduction}

Whey is a byproduct of cheese production, relatively inexpensive with a high nutritional value containing a variety of proteins with unique physical, chemical and functional properties (Cerqueira et al., 2014; McIntosh et al., 1998; Ramos et al., 2015). $\beta$ Lactoglobulin ( $\beta-\mathrm{Lg}$ ) is the main protein in whey (i.e. $50 \%$ of whey protein composition), with a well-known ability to form threedimensional networks (i.e. gel formation), foams and stable nanostructures. These nanostructures can associate to other compounds,

\footnotetext{
* Corresponding author.

E-mail address: rpereira@deb.uminho.pt (R.N. Pereira).
}

thus improving their adsorption in the intestine by increasing residence time, enhancing contact with epithelial membrane, therefore contributing to a higher bioavailability (Diarrassouba, 2013; Giroux \& Britten, 2011; Gunasekaran, Ko, \& Xiao, 2007).

This lipocalin protein encompasses nine antiparallel $\beta$-barrels with three $\alpha$-helixes on the outer surface, a free thiol group, responsible for its antioxidant activity and contains four binding sites (the calix, the gap near the $\alpha$-helix on the outer surface, the dimer interface and the outer surface near tryptophane19aginine124), which makes $\beta$ - $\mathrm{Lg}$ a suitable bio-based vehicle for transportation of various functional compounds, particularly those which are poorly soluble in water and susceptible to degradation by chemical and light reactions (such as riboflavin) (Diarrassouba, 2013; Diarrassouba, Liang, Remondetto, \& Subirade, 2013; Giroux 
\& Britten, 2011; Madureira, Pereira, Gomes, Pintado, \& Malcata, 2007; Zimet \& Livney, 2009).

Structures used in the nanometer scale exhibit a large surface area-to-volume ratio and their physical and chemical interactions influence their overall properties, in particular encapsulation of nutraceuticals. For instance, a change in their pharmacokinetics and biodistribution, contributes to the improvement of nutraceuticals' solubility and bioavailability, thus preventing undesirable chemical reactions and maintaining its activity until its release (Cerqueira et al., 2014; Lingyun Chen, Remondetto, \& Subirade, 2006; Ramos et al., 2015).

Riboflavin (also known as vitamin $\mathrm{B}_{2}$ ) is a biocompatible flavin that can easily be found in Nature (in wheat bran, meat, milk, cheese and plant materials). This vitamin is essential for growth, development and normal maintenance of the human body, but very susceptible to light degradation and poorly soluble in water (Ball, 2004; Cerqueira et al., 2014; Diarrassouba et al., 2013). On the other hand, upon light activation, riboflavin can also cause damage to DNA, proteins and other biomolecules. Therefore, this vitamin can effectively act as a nutraceutical against antibiotic resistant pathogens found in food products and in prevention of some types of cancers (e.g. leukemia) (Diarrassouba et al., 2013). When ingested, the $\beta$ - $\mathrm{Lg} /$ riboflavin nanocomplex will be subjected to innumerous conditions (i.e. pH variations, enzymatic action, peristaltic movements and temperature), in the gastrointestinal (GI) tract, that can change their structure, thus reducing their effectiveness. Therefore, it is crucial to evaluate the behavior of such nanocomplex in the GI tract physiological conditions in order to understand the effects on the nanostructure stability, in particular regarding the release of riboflavin with the purpose of optimizing its bioavailability (Cerqueira et al., 2014).

Studies were found in the literature addressing complexes made from whey proteins and bioactive compounds under GI conditions. Diarrassouba et al. (2013) studied the effects of GI pH conditions on the stability of $\beta$ - $\mathrm{Lg} /$ vitamin $\mathrm{D}_{3}$ nanocomplex. They concluded that $\beta$ - $\mathrm{Lg} / \mathrm{D}_{3}$ nanocomplex is stable under acidic (4.0-2.5) and alkaline (6.8-8.0) transitions, suggesting that it might be stable throughout the GI tract transit. Picot and Lacroix (2004) studied the encapsulation efficiency of bifidobacteria in whey protein-based microcapsules and their survival in simulated GI conditions. They concluded that encapsulation of bifidobacteria provided a protective effect during the GI simulation (i.e. $\mathrm{pH} 1.9$ and gastric enzymes - in stomach simulation; and $\mathrm{pH} 7.5$ and pancreatic and bile salts in intestinal simulation) tested at $37{ }^{\circ} \mathrm{C}$. Le Maux et al. (2013) studied the $\beta-\mathrm{Lg} /$ linoleate complex under in vitro digestion conditions $(0.15 \mathrm{~mol} / \mathrm{L} \mathrm{NaCl}$ and $\mathrm{pH} 2.5$ - gastric fluid simulation; and $0.15 \mathrm{~mol} / \mathrm{L} \mathrm{NaCl}$ and $\mathrm{pH} 6.5$ - duodenal fluid simulation), linoleate bioaccessibility, as well as its intracellular transport into intestinal epithelial Caco- 2 cell lines. They concluded that the formation of $\beta$ $\mathrm{Lg} /$ linoleate complex modified the linoleate transport and delayed the cytotoxicity of the fatty acids. However, the GI models used in these studies only mimic the gastric and duodenal conditions being poorly accurate regarding GI tract enzymatic conditions. Therefore, the present work intends to go deeper in this matter in order to better understand the behavior of bio-based nanostructures, as well as the bioavailability of associated bioactive compounds, when subjected to different physicochemical mechanisms. Hence, nanostructures made from $\beta-\mathrm{Lg}$ and loaded with riboflavin were critically characterized in terms of their morphology (i.e. particle diameter, polydispersity and $\zeta$-potential, shape) by dynamic light scattering (DLS) and transmission electron microscopy (TEM), and the efficiency to associate riboflavin by spectrofluorimetry. Furthermore, these nanocomplexes were evaluated through an in vitro GI model, simulating the physiological conditions (i.e. $\mathrm{pH}$, enzymes, salts and temperature) and time in the stomach and small intestine (including duodenum, jejunum and ileum) in order to address the main challenges regarding the bioavailability of riboflavin and its controlled release in different GI conditions. This study also provides information about the stability of such nanocomplexes when incorporated in water (used as control) and in a food model system (i.e. yoghurt) during 14 days of storage, aiming at their application in the food industry.

\section{Materials and methods}

\subsection{Materials}

Riboflavin with a purity $\geq 98 \%$ and bovine $\beta$ - $\mathrm{Lg}$ containing variants A and B (36.0 kDa) with a purity $\geq 90 \%$ (L0130), were purchased as a lyophilized powder from Sigma-Aldrich (St. Louis MO, USA). Pepsin (600 $\mathrm{U} \mathrm{ml}^{-1}$ ) from porcine gastric mucosa, lipase $\left(40 \mathrm{U} \mathrm{ml}^{-1}\right)$, pancreatin from porcine pancreas $(8 \times \mathrm{USP})$, bile extract porcine, as well as gastric and small intestinal electrolyte solution salts were also purchased from Sigma-Aldrich (St. Louis MO, USA). Ultrapure water (resistivity $18.2 \mathrm{M} \Omega / \mathrm{cm}$ ) was obtained with a Milli-Q Ultrapure water purification system (Millipore, Bedford MA, USA). Sodium hydroxide ( $\mathrm{NaOH}$ ) and hydrochloric acid $(\mathrm{HCl})$ solutions were obtained from Panreac (Panreac Quimica SA, Barcelona, Spain). Coomassie brilliant blue (250) (CBB) was purchased from Sigma-Aldrich (St. Louis MO, USA), whereas sodium azide $\left(\mathrm{NaN}_{3}\right)$ was obtained from Merck (Darmstadt, Germany). All other chemicals were reagent-grade or higher, and were used without further purification.

\subsection{Measurements}

\subsubsection{Dynamic light scattering}

The particle diameter, polydispersity index (PDI) and $\zeta$-potential of protein solution were measured by dynamic light scattering (DLS) using a Zetasizer Nano ZEN 3600 (Malvern Instruments, Worcestershire, UK) equipped with a $\mathrm{He}-\mathrm{Ne}$ laser of $632.8 \mathrm{~nm}$ and $4 \mathrm{~mW}$. Measurements of DLS were collected applying backscatter detection NIBS (Non-Invasive Back-Scatter) at $173^{\circ}$, which reduces multiple scattering and allows higher concentrations to be measured (Rodrigues et al., 2015). Samples (1 mL) of unheated and heated $\beta$-Lg solutions collected at different stages of in vitro digestion were poured into disposable sizing cuvettes with a path length of $12 \mathrm{~mm}$ for particle diameterand PDI determination and into a folded capillary cell for $\zeta$-potential analyses and measurements were carried out, at least, in triplicate. To analyze the samples resulting from the in vitro digestion experiment, a dilution of a $1: 100(\mathrm{v} / \mathrm{v})$ ratio was made in the appropriate $\mathrm{pH}$ conditions $(\mathrm{pH} 2$ and 7 for stomach and small intestine, respectively) to avoid multiple scattering effects. The temperature of analysis was maintained at $25.0 \pm 0.5^{\circ} \mathrm{C}$ during measurement. Average diffusion coefficients were determined by the method of cumulants fit and were translated into average particle diameters $\left(Z_{\text {avg }}\right)$ using Stokes-Einstein relationship (Rodrigues et al., 2015). PDI derived from cumulants analysis of the DLS measurements was also evaluated and describes the width or the relative variance of the particle diameter distribution. The $\zeta$-potential was performed with an angle of $17^{\circ}$ by measuring the velocity and direction of droplet movement in the electric field being calculated through the Smoluchowski model.

\subsubsection{Transmission electron microscopy}

The surface morphology of the $\beta$-Lg nanostructures was evaluated by transmission electron microscopy (TEM) (Zeiss EM 902A Thornwood, N.Y., USA) at an accelerating voltage of 50 and $80 \mathrm{kV}$. The samples were previously prepared by dropping $\beta$-Lg samples onto copper grids coated with carbon film, followed by natural 
drying for 2 min and the excess was removed with absorbent paper. The samples were then negatively stained with uranyl acetate (2\% $\mathrm{w} / \mathrm{w}$ ) (Merck, Germany) for $15 \mathrm{~s}$, and the grid was air-dried at room temperature before introducing it in the electron microscope (Bourbon et al., 2015; Pinheiro et al., 2015).

\subsubsection{Spectrofluorimetry}

Spectrofluorimeter (Jasco FP6200, Tokyo, Japan) was used to assess the association efficiency of riboflavin, and to quantify its release over time during the in vitro digestion and stability assays. This vitamin presents fluorescence properties (Sá, da Silva, Jost, \& Spinelli, 2015), which enable its study on a spectrofluorimeter. All samples were previously centrifuged at $5000 \mathrm{~g}$, for $30 \mathrm{~min}$ at $5{ }^{\circ} \mathrm{C}$ to separate the $\beta$ - $\mathrm{Lg}$ nanostructures from free riboflavin in order to avoid misleading results. The fluorescence intensity spectra of supernatants were then recorded between 480 and $650 \mathrm{~nm}$, with an excitation wavelength set to $450 \mathrm{~nm}$.

\subsubsection{Native polyacrylamide gel electrophoresis}

In order to understand the behavior of $\beta$ - $\mathrm{Lg}$ in GI conditions, a native polyacrylamide gel electrophoresis (native PAGE) was performed. The native PAGE was carried out using the Mini-Protean II dual slab cell system equipped with a PAC 300 power supply (BioRad Laboratories, Hercules, CA, USA). The resolving and stacking gel contained $12 \%$ and $4 \%$ of polyacrylamide, respectively. The gels were left in gentle agitation overnight in a solution of ethanol 50\% and acetic acid $10 \%$ and stained with CBB and destained with a 30 and $7 \%$ of ethanol and acetic acid solutions, respectively, according to previous works (Bourbon et al., 2015; L. Chen \& Subirade, 2005; Rodrigues et al., 2015).

\section{3. $\beta$ - $\mathrm{Lg} /$ riboflavin nanocomplex}

\subsubsection{Production}

$\beta$ - $\mathrm{Lg}$ nanostructures were prepared according to previously optimized conditions (Branco, 2015) where various parameters were assessed (i.e. protein and vitamin concentrations, time of heating, centrifugal time and $g$ force employed). Therefore, a solution of $\beta-\mathrm{Lg}$ at $0.5 \%(\mathrm{w} / \mathrm{v})$ was prepared via dissolution in ultrapure water and subsequently stirred for $2 \mathrm{~h}$ at room temperature, and then $\mathrm{pH}$ was adjusted to 6.0 with $\mathrm{HCl}(1 \mathrm{~mol} / \mathrm{L})$ or $\mathrm{NaOH}(1 \mathrm{~mol} /$ $\mathrm{L})$, as necessary. Afterward, the $\beta$ - $\mathrm{Lg}$ solution was heated at $80^{\circ} \mathrm{C}$ for $10 \mathrm{~min}$. A riboflavin solution was finally added to attain a final concentration of $0.0006 \%(\mathrm{v} / \mathrm{v})$. During this process, the vitamin solution was protected from light exposure with aluminum foil. The resulting solution was then cooled in ice for $15 \mathrm{~min}$.

\subsubsection{Association efficiency}

Association efficiency (AE) was assessed by comparing the total riboflavin concentration (from riboflavin solution) with the concentration of riboflavin unattached to $\beta$-Lg. Primarily, $1 \mathrm{~mL}$ of both riboflavin at $0.0006 \%(\mathrm{v} / \mathrm{v})$ (riboflavin solution), and samples ( $\beta-\mathrm{Lg} /$ riboflavin nanocomplex) were placed into Eppendorf tubes and centrifuged. Then, $0.1 \mathrm{~mL}$ of supernatant was collected and fluorescence spectral analysis was obtained. The maximum absorbance peaks, from the fluorescence spectra, of riboflavin and supernatant were used to determine the riboflavin concentration (calculated using an appropriate calibration curve of riboflavin: $y=99,624 x+8.3344, R^{2}=0.991$; being $y$ and $x$ the absorbance and concentration of free riboflavin, respectively) and the results were used on Eq. (1).

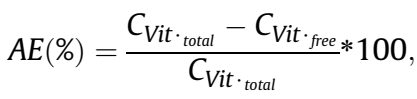

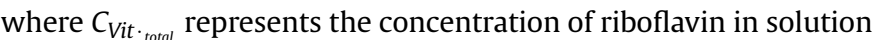
and $C_{V i t}$.riee the concentration of free riboflavin separated from $\beta-\mathrm{Lg}$ nanostructures The determinations were performed at least in triplicate.

\subsection{In vitro digestion}

The in vitro digestion experiment was performed in a GI model constituted by a double-walled water-jacketed reactor vessel (10 cm internal diameter and $15 \mathrm{~cm}$ height), adapted from Pinheiro et al. (2013). Primarily, the loss of activity of free riboflavin was assessed in the in vitro GI model and it was observed that only $56 \pm 10,40 \pm 8,24 \pm 3$ and $16 \pm 4 \%$ would reach the stomach, duodenum, jejunum and ileum, respectively. These results confirm the necessity of its encapsulation in order to allow its protection during the in vitro digestion. $\beta$ - $\mathrm{Lg} /$ riboflavin solution $(40 \mathrm{~mL})$ was inserted into the GI simulator, the temperature was set to $37^{\circ} \mathrm{C}$ and appropriate secretions were continuously added, in order to mimic the physiological conditions of the GI tract (i.e. stomach, duodenum, jejunum and ilium). All samples were taken at the end of each phase. The in vitro digestion conditions are resumed in Table 1. All $\mathrm{pH}$ transitions were accomplished by adding $\mathrm{HCl}(1 \mathrm{~mol} / \mathrm{L})$ and sodium bicarbonate $(1 \mathrm{~mol} / \mathrm{L})$ for gastric and small intestine $\mathrm{pH}$ conditions, respectively.

\subsection{Stability assessment}

The stability of $\beta-\mathrm{Lg} /$ riboflavin nanocomplex was assessed in a food model system solution composed by $3 \%$ of acetic acid at $\mathrm{pH}$ 3.65 , to mimic yoghurt, according to the Commission Regulation (EU) No 10/2011 for food simulants (European Commission, 2011), and compared with the behavior of such nanocomplex in ultrapure water (used as control). The stability test was conducted during a predetermined period of time (14 days) through evaluation of particle diameter, PDI and $\zeta$-potential variation by DLS, release profile of riboflavin by spectrofluorimetry, and particle morphology by TEM. Microorganism growth was prevented by adding $0.02 \%$ of $\mathrm{NaN}_{3}$ (used as preservative) (Ramos et al., 2012) into the food model system solution. All samples were analyzed immediately after production, in triplicate.

\subsection{Statistical analysis}

All statistical analyses involving experimental data were performed using Statistica software version 10.0.228.8 (StatSoft Inc.). Statistical significance (at $p \leq 0.05$ ) was determined using one-way ANOVA followed by post hoc.

Tukey's tests. Unless otherwise stated, all the following experiments were run at least in triplicate and all measured parameters are means of four experimental points.

\section{Results and discussion}

\subsection{Particle characterization}

The evaluation of particle diameter, PDI and $\zeta$-potential allowed the understanding of some structural changes that occur in $\beta-\mathrm{Lg}$ nanostructure during the heating treatment and incorporation of riboflavin. Characterization of $\beta$ - $\mathrm{Lg} /$ riboflavin nanocomplex by DLS is shown in Table 2.

These results demonstrate that unheated $\beta$ - $\mathrm{Lg}$ solution, at $\mathrm{pH} 6$, 
Table 1

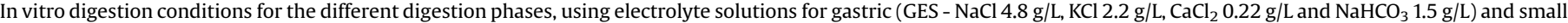
intestine (SIES - NaCl 5 g/L, $\mathrm{KCl} 0.6 \mathrm{~g} / \mathrm{L}$ and $\mathrm{CaCl}_{2} 0.25 \mathrm{~g} / \mathrm{L}$ ) conditions.

\begin{tabular}{|c|c|c|c|c|c|}
\hline Digestion phases & Secretions & Electrolyte solution & Flow $(\mathrm{mL} / \mathrm{min})$ & $\mathrm{pH}$ & Time (h) \\
\hline Stomach & $\begin{array}{l}\text { pepsin } \\
\text { lipase }\end{array}$ & $100 \mathrm{~mL}$ of GES & 0.3 & from 4.8 to 1.7 & 2 \\
\hline Duodenum & $\begin{array}{l}30 \mathrm{~mL} \text { of porcine bile extract at } 4 \%(\mathrm{w} / \mathrm{v}) \\
15 \mathrm{~mL} \text { of pancreatin solution }\end{array}$ & $9 \mathrm{~mL}$ of SIES & 0.6 & 6.5 & 1 \\
\hline Jejunum & $20 \mathrm{~mL}$ of porcine bile extract & $200 \mathrm{~mL}$ of SIES & 2.1 & 6.8 & 1 \\
\hline Ileum & - & $150 \mathrm{~mL}$ of SIES & 2.0 & 7.2 & 1 \\
\hline
\end{tabular}

Table 2

Particle size, PDI and $\zeta$-potential values obtained for $\beta$ - $\mathrm{Lg}$ nanostructures before and after heating treatment, as well as after riboflavin association.

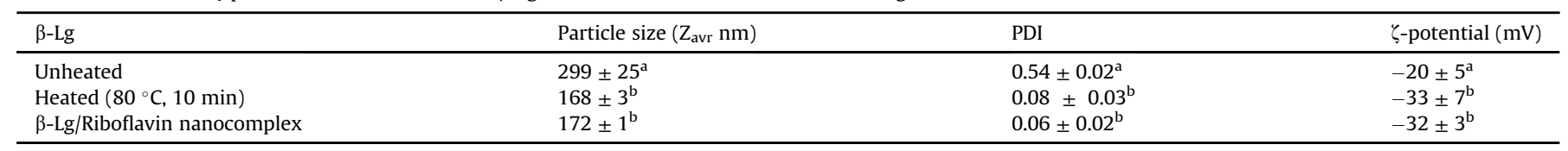

Note: Means within a given column, labeled with the same superscript letter (a or b) do not statistically differ from each other ( $p>0.05$ ).

presents a significant degree of heterogeneity (confirmed by the high standard deviation obtained for particle diameter and PDI values). This heterogeneity may be due to non-covalent linked protein aggregates which are commonly observed on its native form (Pereira, Souza, Cerqueira, Teixeira, \& Vicente, 2010; Ramos et al., 2014). This protein system appears to be on a semi-stable state when looking to the $\zeta$-potential value $(-20 \pm 5 \mathrm{mV})-$ it is considered that $\zeta$-potential values above $+30 \mathrm{mV}$ and below $-30 \mathrm{mV}$, for this kind of nanostructures, represent stable colloidal systems (Diarrassouba, 2013; Moore \& Cerasoli, 2010). However, this colloidal stability can always be compromised with interaction of oppositely charged polymers and particles. Denaturation was then promoted by heating the $\beta$ - $\mathrm{Lg}$ solution $\left(80^{\circ} \mathrm{C}\right.$ for $10 \mathrm{~min}$ ), which caused alterations on particle diameter, PDI and $\zeta$ potential. After heating, the protein solution became more stable ( $\zeta$-potential changed from $-20 \pm 5$ to $-33 \pm 7 \mathrm{mV}$ ) and homogeneous. Moreover, PDI values decreased from $0.54 \pm 0.02$ to $0.08 \pm 0.03$ and particle diameter was reduced approximately to half of its initial value (i.e. decreased from $299 \pm 25$ to $168 \pm 3 \mathrm{~nm}$ ). The heating process may allow dissolving some protein aggregates that could be present in the native solution at ambient temperature, while also promoting structural rearrangements by breaking at least some of the disulfide bonds, resulting in protein unfolding and exposure of its sulfhydryl groups. The sulfhydryl groups may form inter- and intra-molecular bonds by interacting with other disulfide bonds which, together with inter-molecular interactions between proteins, will determine protein aggregation (Pereira et al., 2010). After cooling, aggregation of $\beta$-Lg occurs (Kolakowski, Dumay, \& Cheftel, 2001) through new intra-molecular disulfide bonds leading to the reduction of particle diameter distribution. The addition of riboflavin did not produce significant $(p>0.05)$ changes in the particle diameter, PDI or $\zeta$-potential values (see Table 2). Incorporation of riboflavin into the solution was made while $\beta$ - $\mathrm{Lg}$ was on its molten globule state. At this state, the partial unfolding of $\beta$-Lg and the increase in flexibility of some structural regions (but still preserving the calyx) enables the exposure of the inner binding site, making it more easily accessible (Tavel, Moreau, Bouhallab, Li-Chan, \& Guichard, 2010) to riboflavin, which possibly allowed its association to the protein network with an $\mathrm{AE}$ of $26 \pm 1 \%$. This value was relatively lower when compared with that obtained by Azevedo, Bourbon, Vicente, and Cerqueira (2014), which showed an $\mathrm{AE}$ of $56 \pm 6 \%$ for riboflavin using nanoparticles made from alginate/chitosan as base materials, besides a high heterogeneity associated to these systems (Azevedo et al., 2014). This difference could be explained by the nature of the different encapsulating agents employed (in that case, the authors used the combination of two polysaccharides for the nanostructures' production), as well as by the different production conditions (e.g. $\mathrm{pH}$ of 4.6 and 4.9) applied. It is known that, despite the lack of toxicity, the recommended daily dose (RDD) for riboflavin is approximately $1.2 \mathrm{mg}$ (Horwitt, Harvey, Hills, \& Liebert, 1949; Powers, 2003). Therefore due to an $\mathrm{AE}$ of $26 \pm 1 \%$, the results show that $12 \%$ of the RDD would reach the small intestine if $100 \mathrm{~mL}$ of a food product was ingested, suggesting that this nanocomplex may find applications as a food supplement system. Hence, it can be incorporated into healthy food products that have already some content of riboflavin in their composition in order to overcome potential nutritional deficiencies.

Despite of the fact that the nanocomplex produced here showed to be more stable than those reported elsewhere, comparisons should be carefully made once conditions/compounds employed and purposes vary significantly (Pereira et al., 2010). Yi et al. (2014) produced $\beta$ - $\mathrm{Lg} /$ dextran nanoparticles for controlled release of $\beta$ carotene. They obtained $\beta$-Lg/dextran nanoparticles with a mean particle diameter of $68 \pm 3 \mathrm{~nm}$, PDI of $0.17 \pm 0.03$ and $\zeta$-potential of $-14 \pm 1 \mathrm{mV}$. They obtained a lower particle diameter than those mentioned in this work. That can be explained by different sample preparation or conditions used (i.e. nanostructures formed by the mixture of different polymers - dextran and $\beta$ - $\mathrm{Lg}$ - prepared at $\mathrm{pH} 7$ and $\beta-\operatorname{Lg}$ at $1 \%)$. However the nanocomplex formed seems to be less stable( $\zeta$-potential of $-14 \pm 1 \mathrm{mV}$ ) according with the definition of stability for colloidal systems aforementioned (Diarrassouba, 2013; Moore \& Cerasoli, 2010), thus being probably less suitable as carrier systems for nutraceuticals, when compared with the results presented here for $\beta$ - $\mathrm{Lg}$ nanostructures (Table 2). Chen and Subirade (2005) produced chitosan $/ \beta$ - Lg core-shell nanoparticles for controlled release of nutraceuticals. They studied the influence of $\mathrm{pH}$ on particle diameter and $\zeta$-potential. At $\mathrm{pH}$ 6.1, they obtained a particle diameter of $103 \mathrm{~nm}$, PDI of 0.54 and $\zeta$-potential of $+30 \mathrm{mV}$. Despite the lower particle diameter obtained (which can be explained by the nanocomplex formation between chitosan and $\beta$ $\mathrm{Lg})$ their nanosystem presented a high degree of heterogeneity which suggests the existence of particles on other scale ranges. Thus, the authors cannot assure the measurement of particles only in the nanometer range.

\subsection{In vitro digestion}

During digestion, food undergoes two main processes (that occur simultaneously): the influence of mechanical movements 
(i.e. peristaltic movements) to reduce the diameter of food particles, and enzymatic action where macromolecules are hydrolyzed to form more basic, smaller structures able to be subsequently absorbed into the bloodstream (Guerra et al., 2012; Kong \& Singh, 2008; Pinheiro, 2013).

In order to understand the behavior of $\beta$ - $\mathrm{Lg}$ nanostructures loaded with riboflavin in GI conditions, an in vitro GI model was used to simulate as close as possible the human GI tract. Therefore, said nanostructures were characterized in terms of their structure (i.e. particle diameter, PDI and $\zeta$-potential), capacity to associate to and release riboflavin.

\subsubsection{Structural characterization of $\beta$ - $L g$ nanostructures}

A structural analysis was made in order to understand the influence of digestion conditions on $\beta$-Lg nanostructures loaded with riboflavin, resorting to DLS measurements, and the results are depicted in Table 3.

From the DLS results depicted above, it was possible to observe that $\beta$ - $\mathrm{Lg} /$ riboflavin nanocomplex possibly suffered aggregation throughout the digestive process, as well as an increase in its heterogeneity. These findings are inferred from the increase in particle diameter and PDI values, respectively, along the passage through the different GI conditions. Although, it was not possible to determine the precise mechanism that caused the structural changes in the nanostructures but the increase in particle diameter could be explained by the presence of bile salts, digestive enzymes, or by the combined effect of pH and ionic strength (Pinheiro, 2013). During the stomach step, $\beta$-Lg nanostructures were subjected to enzymatic digestion (pepsin and lipase) and acidic $\mathrm{pH}$ conditions (from 4.8 to 1.7), which influence the conformation of the nanostructure, as well as its $\zeta$-potential. The passage through the pI value of $\beta-\mathrm{Lg}(\mathrm{pH}$ of 5.2) may influence its structure and can be the cause of the particle diameter difference between the initial and gastric conditions (Griffin, Griffin, Martin, \& Price, 1993) and its surface charge, observable on the transition from a $\zeta$-potential value of $-37 \pm 1$ to $+28 \pm 2 \mathrm{mV}$ (i.e. $\mathrm{pH}$ values below pI promote a positively charged protein surface) (Diarrassouba, 2013). Despite of the changes, when comparing with the initial state, the nanostructure remained homogenous and stable supported by low PDI value $(\mathrm{ca} .<0.2)$ and high $\zeta$-potential value (ca. $+30 \mathrm{mV}$ ), respectively - see Table 3 . To confirm the results obtained by DLS, a native PAGE was performed - see Fig. 1 - since it enables the separation of $\beta$-Lg aggregates by charge, particle diameter and shape (Rodrigues et al., 2015).

From the analysis of Fig. 1, it is possible to observe that in lane 1, unheated $\beta-\mathrm{Lg}$ nanostructures are more likely to aggregate at $\mathrm{pH} 6$, which is near the pI of $\beta-\operatorname{Lg}$ (i.e. $\mathrm{pH}$ value of 5.2) which leads to the formation of small and unstable protein aggregates (Diarrassouba, 2013). Smears in lane 2 can be attributed to heat denaturation of native $\beta$ - Lg and concomitant appearance of high molecular mass protein aggregates as reported elsewhere (Rodrigues et al., 2015). Comparing lane 2 ( $\beta$ - $\mathrm{Lg} /$ riboflavin nanocomplex) used as control with lane 4 ( $\beta-\mathrm{Lg} /$ riboflavin nanocomplex in stomach), is quite

Table 3

Particle size, PDI and $\zeta$-potential values of $\beta$-Lg/riboflavin nanocomplex at different stages of digestion $(0 \mathrm{~h}-$ control, $2 \mathrm{~h}-$ stomach, $3 \mathrm{~h}-$ duodenum, $4 \mathrm{~h}-$ jejunum and $5 \mathrm{~h}-$ ileum).

\begin{tabular}{llll}
\hline Digestion phase & Size $(\mathrm{nm})$ & PDI & $\zeta$-potential $(\mathrm{mV})$ \\
\hline Control & $232 \pm 21^{\mathrm{a}}$ & $0.16 \pm 0.07^{\mathrm{a}}$ & $-37 \pm 1^{\mathrm{a}}$ \\
Stomach & $329 \pm 23^{\mathrm{a}}$ & $0.16 \pm 0.06^{\mathrm{a}}$ & $28 \pm 2^{\mathrm{b}}$ \\
Duodenum & $826 \pm 334^{\mathrm{b}}$ & $0.68 \pm 0.13^{\mathrm{b}}$ & $-27 \pm 4^{\mathrm{c}}$ \\
Jejunum & $726 \pm 226^{\mathrm{b}}$ & $0.65 \pm 0.10^{\mathrm{b}}$ & $-36 \pm 3^{\mathrm{a}}$ \\
Ileum & $859 \pm 288^{\mathrm{b}}$ & $0.68 \pm 0.15^{\mathrm{b}}$ & $-34 \pm 3^{\mathrm{a}}$ \\
\hline
\end{tabular}

Note: Means within a given column, labeled with the same superscript letter (a, b, c), do not statistically differ from each other $(p>0.05)$.

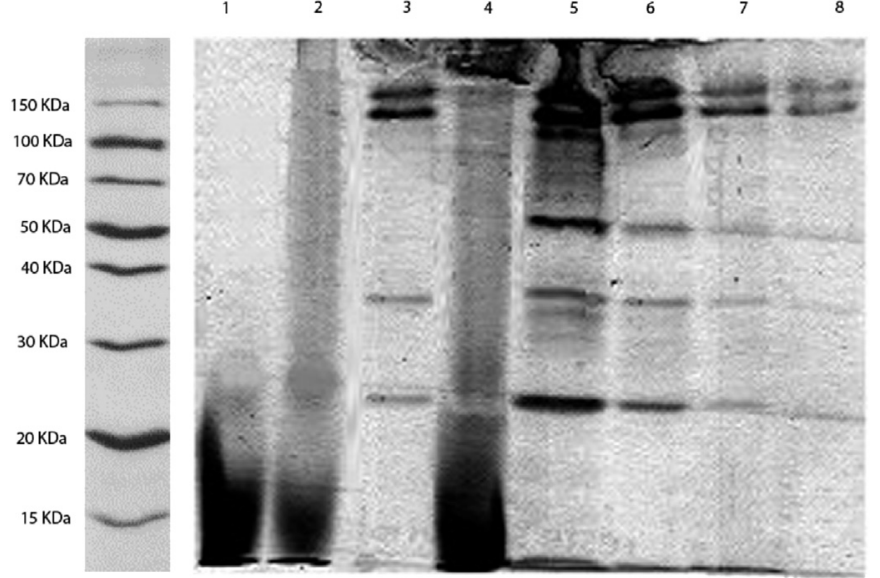

Fig. 1. Native PAGE of $\beta$ - $\operatorname{Lg}$ nanostructures loaded with riboflavin at different stages of the GI tract: 1 - native $\beta$ - $\mathrm{Lg}$ (without heat treatment); $2-\beta$ - $\mathrm{Lg} /$ riboflavin nanocomplex; 3 and 5 stomach and duodenum control (GES and SIES, respectively); 4, 6, 7 and 8 - $\beta$ $\mathrm{Lg} /$ riboflavin nanocomplex in stomach, duodenum jejunum and ileum, respectively.

evident the presence of $\beta$ - $\mathrm{Lg} /$ riboflavin nanocomplex in the stomach phase. This may indicate that $\beta-\operatorname{Lg}$ nanostructures are resistant to proteolytic and $\mathrm{pH}$ conditions of stomach. In lane 4 , protein smears may result from acid aggregation during transition through isoelectric point, promoted by the in vitro stomach $\mathrm{pH}$ conditions. From lane 5 to $8, \beta$ - $\mathrm{Lg} /$ riboflavin nanocomplex was not observed when compared with lane 2 (control), which may indicate that such nanocomplex was completely degraded in the intestinal phase of the GI system, possibly as soon as it reached the duodenum (Fig. 1). Despite of $\beta$-Lg endurance in the stomach, during intestinal digestion $\beta$-Lg is very susceptible to small intestine enzymatic hydrolysis (i.e. pancreatin), which leads to $\beta$-Lg digestion in the small intestine (Fu, Abbott, \& Hatzos, 2002; Mandalari et al., 2009). The loss of color progressively observed from lane 6 to 8 may be due to the dilution effect of the samples, as a consequence of in vitro digestion protocol (constant addition of electrolyte solutions) (Pinheiro et al., 2013).

The DLS and electrophoretic results suggest that $\beta$-Lg is resistant to enzyme digestion in the stomach. This resistance can be explained by the fact that most hydrophobic amino acids are buried inside the $\beta$-barrel, due to its stable globular tertiary structure, which makes pepsin digestion a more difficult process (Bateman, Ye, \& Singh, 2010; Peram, Loveday, Ye, \& Singh, 2013). Regarding the passage of $\beta-\operatorname{Lg}$ through the small intestine, the DLS analysis could be misleading. Due to high PDI values in the small intestine (probably due to the presence of bile salts and enzymes), DLS analysis may not be the best analytical method to measure the structural changes that may occur in the small intestine phase. Therefore, the electrophoretic technique was performed and the results showed that $\beta-\operatorname{Lg}$ nanostructures were degraded in the duodenum since the correspondent band is not observable on the subsequent digestion stages. This behavior was also reported by other authors (Bossios et al., 2011; Fu et al., 2002; Islam, Ekeberg, Rukke, \& Vegarud, 2015). Fu et al. (2002) studied the digestibility of food allergens and non-allergenic proteins under simulated GI conditions. One of the food allergens studied was $\beta-\operatorname{Lg}$ which showed to be highly resistant to gastric digestion but rapidly degraded in the small intestine, being mostly digested by pancreatic enzymes. Bossios et al. (2011) studied the effect of simulated GI conditions on the allergenic reactivity of $\beta$ - Lg. They concluded that $\beta$-Lg resisted the harsh gastric conditions but was susceptible to pancreatic enzymes in the small intestine. Islam et al. (2015) studied the in vitro digestion of milk focusing on proteolysis and 
lipolysis. They observed that $\beta$-Lg was resistant to pepsin digestion but was degraded by pancreatic enzymes. They also concluded that bile salts influence significantly the digestion of $\beta$-Lg.

In this work, it was shown that $\beta$-Lg is a bio-based carrier that has the ability to protect an active compound from gastric conditions (i.e. acidic $\mathrm{pH}$ and enzymatic activity). In contrast, under intestinal conditions, our results and reports described elsewhere indicate that $\beta-\mathrm{Lg}$ and its genetic variants are degraded mainly due to bile salts concentration and presence of pancreatin that influences its digestion rate (Bossios et al., 2011; Fu et al., 2002; Islam et al., 2015). Therefore, it should be expected that riboflavin release took place in the small intestine. As such, in order to verify this hypothesis, the release profile of riboflavin was determined during GI simulation and the results are reported below.

\subsubsection{Release profile of riboflavin}

During in vitro digestion, the release profile of riboflavin was evaluated in order to identify the precise location and quantify its release.

Fig. 2 shows that only $11 \pm 2 \%$ of riboflavin was released during the gastric phase; this result was somehow expected due to $\beta$-Lg resistance to gastric conditions. On the other hand, higher amounts of riboflavin were released in the duodenum, jejunum and ileum, corresponding to 35,38 and $5 \%$ of the total riboflavin encapsulated, respectively. These results are in accordance with the results obtained by native-PAGE, which showed the degradation of $\beta$ - $\mathrm{Lg}$ mostly in the small intestine.

The results presented above show that most riboflavin was released during duodenum and jejunum phases (35 and 38\%, respectively). Being part of the small intestine, the main role of duodenum, jejunum and ileum is to breakdown food constituents into smaller compounds. These compounds are then absorbed through the intestinal walls and the waste products (non-absorbed substances) pass into the large intestine for excretion (Pinheiro, 2013; Thomson, Shaffer, \& Gonska, 2014). Since most of the riboflavin was released in the duodenum and jejunum, it is most likely that riboflavin would be mostly absorbed by the intestinal walls, into the bloodstream.

These results confirm that $\beta$ - $\mathrm{Lg}$ nanostructures can act as protective carriers against gastric conditions, which will allow enhancing the bioavailability of riboflavin and thus improving its absorption in the small intestine.

\subsection{Evaluation of $\beta$ - $\mathrm{Lg} /$ riboflavin stability}

A stability study was conducted in food simulant conditions to evaluate the behavior of $\beta$-Lg over time, mimicking its incorporation in a food product under storage conditions. A structural evaluation of the nanocomplex and a release profile were obtained and the results are shown in Figs. 3 and 4 and Fig. 5, respectively.

Fig. 3 shows that particle diameter, PDI and $\zeta$-potential, remained approximately constant during the experiment time with mean particle diameters of $202 \pm 7$ and $232 \pm 4 \mathrm{~nm}$, PDI values of $0.11 \pm 0.04$ and $0.09 \pm 0.03$, and $\zeta$-potential values of $-37 \pm 2$ and $+37 \pm 1 \mathrm{mV}$, for water and food simulant conditions, respectively. Moreover, the results showed that $\beta-\mathrm{Lg}$, slightly aggregated under food simulant conditions when compared with water conditions (mean particle diameter of $202 \pm 7 \mathrm{~nm}$ instead of $232 \pm 4 \mathrm{~nm}$ in water and food simulant conditions, respectively). This smaller aggregation could be explained by the effect of acetic acid in the protein unfolding properties (Borkar, Rout, \& Hosur, 2012; Liao et al., 2010), which could possibly enable protein aggregation by inducing the formation of intermolecular bonds (Rodrigues et al., 2015). Since we are working with acetic acid at low concentration, the differences observed between water and food simulant conditions were not too prominent. In spite of this, the solution remained homogeneous, with a low PDI value in both water and simulant conditions. Thus, the food simulant conditions did not significantly change the homogeneity of the solution $(p<0.05)$. Regarding the $\zeta$-potential, the change between a negative surface charge (water conditions) to a positive surface charge (simulant conditions) can be explained by the different $\mathrm{pH}$ of the solutions ( $\mathrm{pH} 6$ and 3.65, above and below the $\mathrm{pI}$ of $\beta$-Lg, for water and simulant conditions, respectively) (Diarrassouba, 2013; Donato, Schmitt, Bovetto, \& Rouvet, 2009). These results were corroborated with TEM micrographs (Fig. 4).

These images indicate that $\beta$ - $\operatorname{Lg}$ nanostructures have a spherical shape, with a particle diameter of ca. $200 \mathrm{~nm}$ (in accordance with DLS measurements) in both water and food simulant conditions, suggesting that $\beta$-Lg nanostructures are resistant to food simulant conditions. It is also possible to observe that $\beta$-Lg suffered some structural changes in water (when compared with time 0 from Fig. 4), imperceptible on DLS analysis. It is noticeable that $\beta$ - $\mathrm{Lg}$ in water formed crystal shaped structures after 14 days of storage at $4{ }^{\circ} \mathrm{C}$. Proteins in aqueous solutions tend to quickly aggregate (due to protein unfolding) when submitted to low temperatures (Kolakowski et al., 2001). This characteristic may explain the aggregation of $\beta$ - $\mathrm{Lg}$ in water, after 14 days of storage at low temperature. This effect was not observable for $\beta$ - $\mathrm{Lg}$ under simulant conditions. The presence of acetic acid could enhance the charge density and electrostatic repulsion between proteins (Liao et al., 2010), preventing protein aggregation during storage time. These micrographs also confirm that the particle diameter of $\beta$-Lg

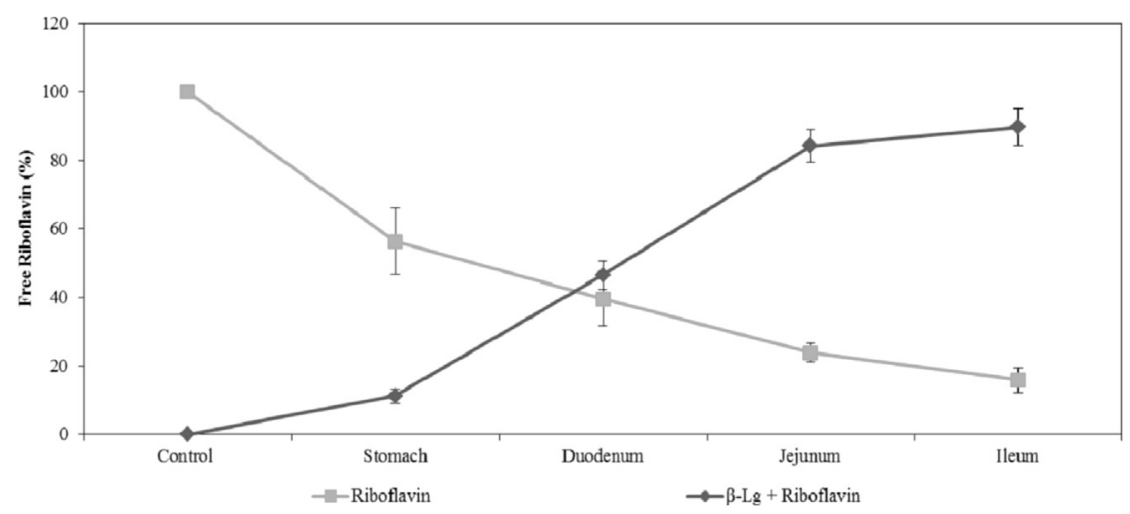

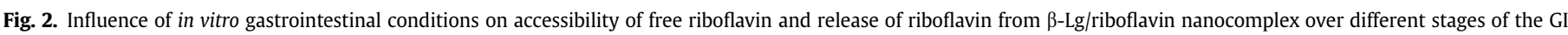
tract during $5 \mathrm{~h}$ of digestion time. 
a
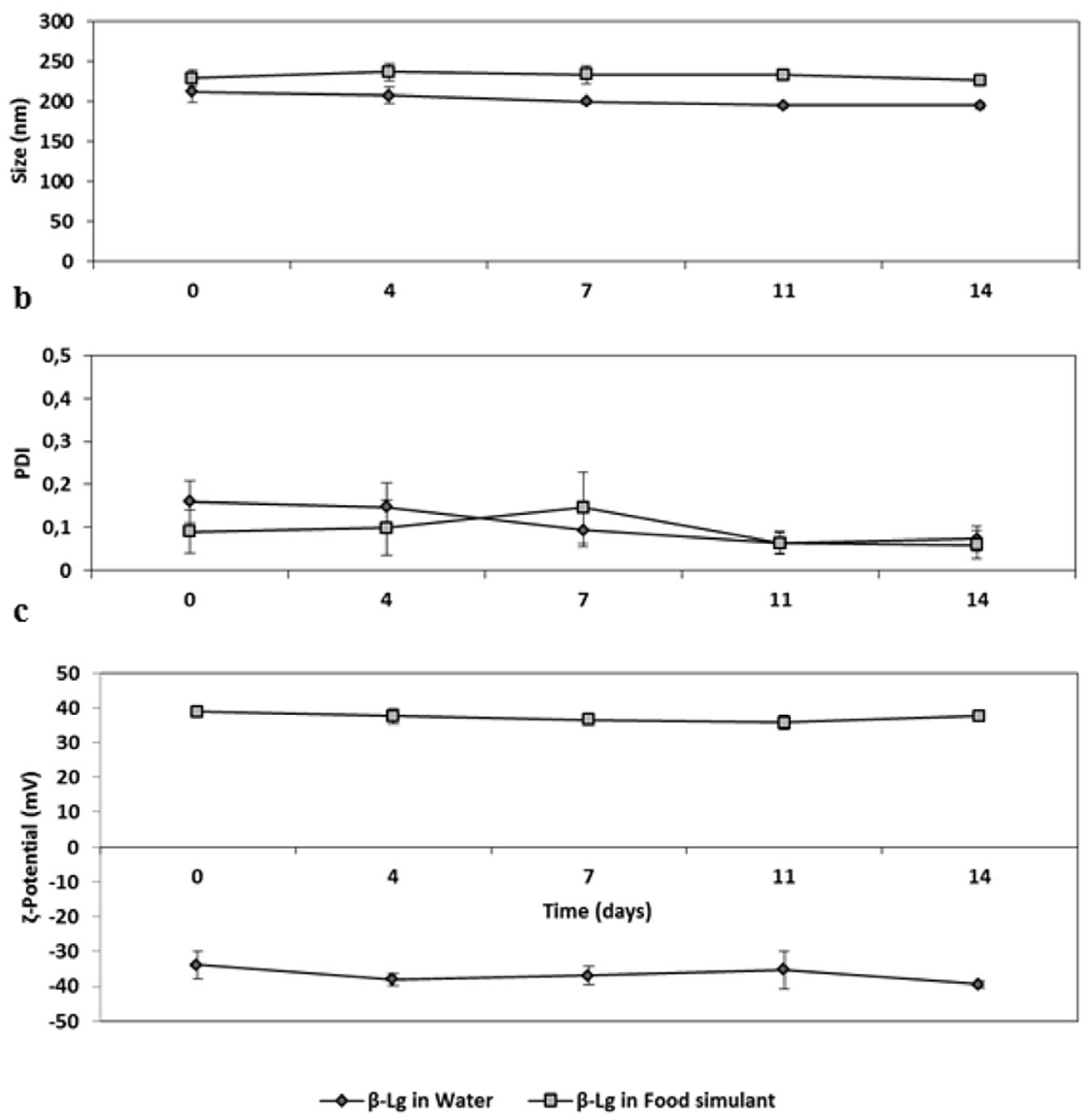

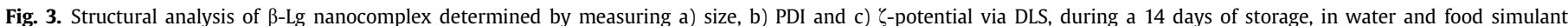
conditions.

A

B

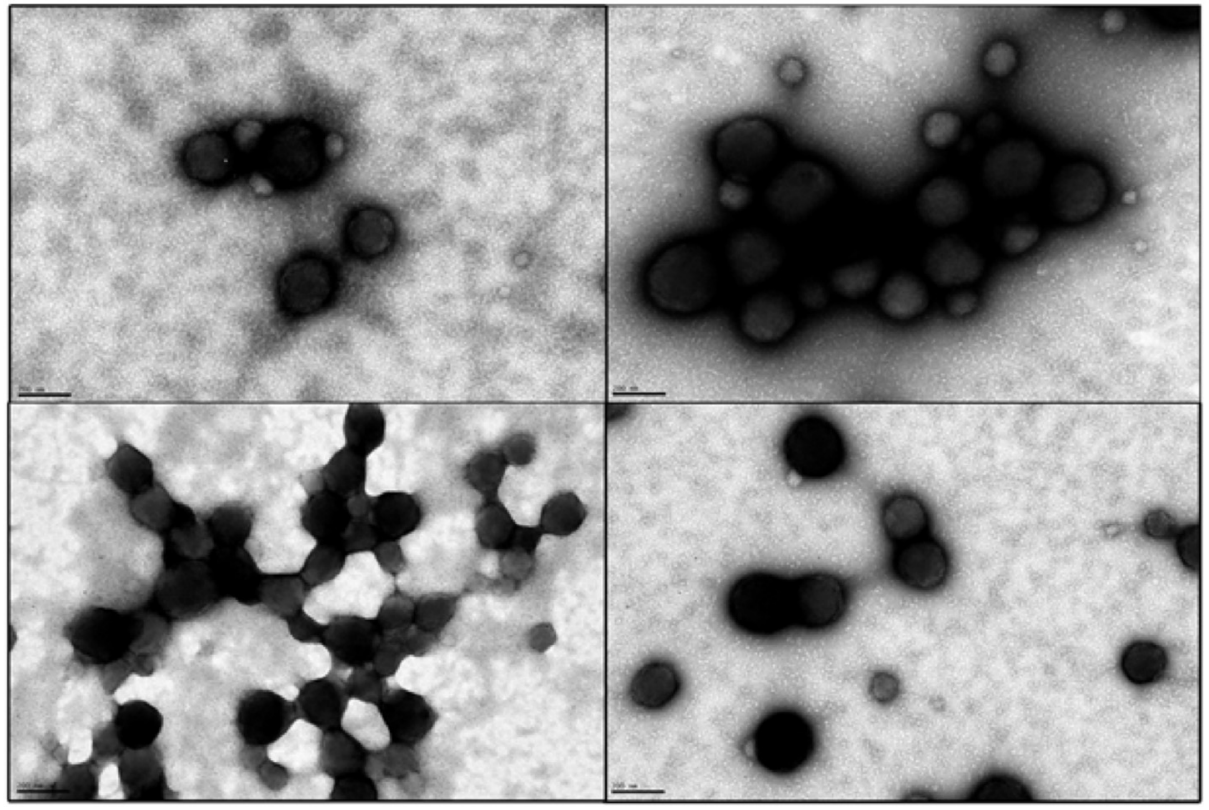

Fig. 4. TEM micrographs of $\beta$-Lg under water (column A - control) and food simulant (column B) conditions, at time 0 (top micrographs) and time 14 (bottom micrographs) (scale bar $=200 \mathrm{~nm}$, magnification $=80,000 \mathrm{x}$ ). 


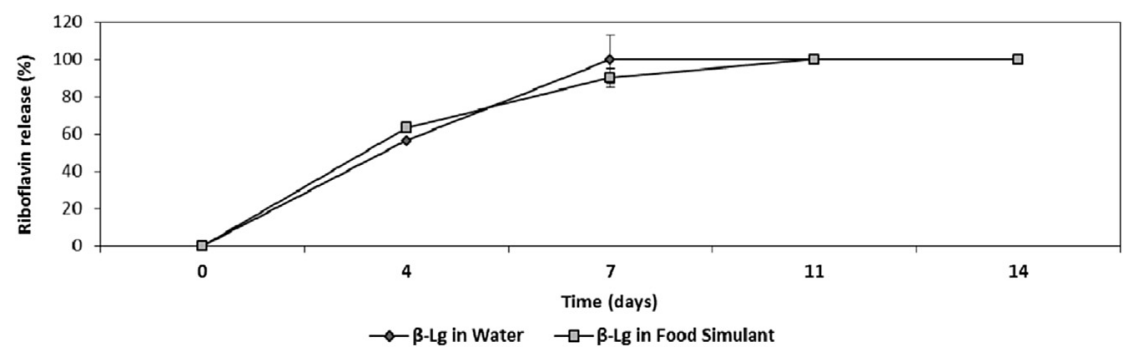

Fig. 5. Riboflavin release profile in water and food simulant conditions during 14 days of storage.

nanostructures remained constant under simulant conditions (when comparisons were made with time 0, Fig. 4), suggesting that proteins remain stable during this 14 days period. Thus, TEM micrographs allowed confirming the lack of structural changes on $\beta$ Lg nanocomplex during the stability assay, under these food simulant conditions.

Despite $\beta$-Lg stability under simulant conditions, a riboflavin release profile was obtained. Results regarding release of riboflavin are shown in Fig. 5 and allowed to determine if $\beta$ - $\operatorname{Lg}$ could serve as a protective carrier for this vitamin during a given storage period (shelf life).

The results shown in Fig. 5 are in accordance with TEM and DLS results. Since $\beta$-Lg did not show significant structural changes over time under food simulant conditions, it was expected that riboflavin remained associated to $\beta$ - $\mathrm{Lg}$ in the food simulant as much as in water. Therefore, $\beta$-Lg gradually released its riboflavin content and, at day 7 , the complete riboflavin release occurred. No significant differences $(p>0.05)$ were observed when comparing water and simulant results, confirming once more that $\beta$ - $\operatorname{Lg}$ was resistant to food simulant conditions.

\section{Conclusions}

Stable and homogenous $\beta$ - $\operatorname{Lg}$ nanostructures were successfully produced at $\mathrm{pH} 6$ to act as protective carriers for nutraceuticals (e.g. riboflavin). It was possible to conclude that not only $\beta$ - $\mathrm{Lg}$ nanostructures have the ability to associate to riboflavin, with an association efficiency of $26 \pm 1 \%$, but they also serve as protective carriers during gastric digestion, releasing the riboflavin content in the appropriate absorption location (i.e. small intestine) once $\beta$ - $\mathrm{Lg}$ is completely degraded as soon as the nanostructures reach the duodenum. Moreover, the results showed that $12 \%$ of RDD would reach the small intestine if $100 \mathrm{~mL}$ of solution was ingested and, thus, this nanostructure could be added to food products to act as a food supplement, in order to help reaching the RDD.

Results show that $\beta$-Lg nanostructure is structurally stable for a period of 14 days under simulant conditions (i.e. yoghurt). The presence of acetic acid may have increase electrostatic repulsion between $\beta-\mathrm{Lg}$, thus preventing its aggregation and enhancing its structural stability. However, regarding riboflavin release, $\beta-\mathrm{Lg} /$ riboflavin nanocomplex is less stable under similar conditions once riboflavin is fully released from protein core after a period of 7 days of storage.

Further tests in a dynamic GI model (as identical as possible to the human GI system) and in Caco-2/HT29-MTX co-cultured cell lines (to mimic, as close as possible, human intestinal cells) will be crucial to evaluate the permeability and absorption rates of riboflavin and to obtain more accurate results in order to better understand and predict the behavior of nanostructured systems under GI simulated conditions. It would also be important to study the behavior of $\beta-\mathrm{Lg} /$ riboflavin nanocomplex under other food simulant conditions such as beverages or starch-based foods, as well as in a real food matrix.

\section{Acknowledgments}

Oscar L. Ramos, Ricardo N. Pereira and Ana C. Pinheiro gratefully acknowledge their Post-Doctoral grants (SFRH/BPD/80766/2011, SFRH/BPD/81887/2011 and SFRH/BPD/101181/2014, respectively) and Ana I. Bourbon gratefully acknowledge her Doctoral grant (SFRH/BD/73178/2010) to Fundação para a Ciência e a Tecnologia (FCT). The authors would like to acknowledge to Francisco Figueiredo from the Institute for Molecular and Cell Biology (IBMC), University of Porto, for assistance in taking the TEM pictures. The authors thank the FCT Strategic Project of UID/BIO/04469/2013 unit, COMPETE 2020 (POCI-01-0145-FEDER-006684), the project RECI/BBB-EBI/0179/2012 (FCOMP-01-0124-FEDER-027462), and the project "BioInd - Biotechnology and Bioengineering for improved Industrial and Agro-Food processes", REF.NORTE-070124-FEDER-000028, co-funded by the Programa Operacional Regional do Norte (ON.2 - O Novo Norte), QREN, FEDER.

\section{References}

Azevedo, M. A., Bourbon, A. I. Vicente, A. A. \& Cerqueira, M. A. (2014). Alginate chitosan nanoparticles for encapsulation and controlled release of vitamin B2. International Journal of Biological Macromolecules, 71, 141-146.

Ball, G. F. M. (2004). Vitamins-their role in the human body (1st ed.). London, UK: Blackwell Publishing Ltd.

Bateman, L., Ye, A., \& Singh, H. (2010). In vitro digestion of beta-lactoglobulin fibrils formed by heat treatment at low pH. Journal of Agricultural and Food Chemistry 58(17), 9800-9808.

Borkar, A., Rout, M. K., \& Hosur, V. (2012). Denaturation of HIV-1 Protease (PR) monomer by acetic acid: mechanistic and trajectory insights from molecular dynamics simulations and NMR. Journal of Biomolecular Structure and Dynamics, 29(5), 893-903.

Bossios, A., Theodoropoulou, M., Mondoulet, L., Rigby, N. M., Papadopoulos, N. G. Bernard, H., et al. (2011). Effect of simulated gastro-duodenal digestion on the allergenic reactivity of beta-lactoglobulin. Clinical and Translational Allergy, 1(1), 6

Bourbon, A. I., Pinheiro, A. C., Carneiro-da-Cunha, M. G., Pereira, R. N., Cerqueira, M. A., \& Vicente, A. A. (2015). Development and characterization of lactoferrin-GMP nanohydrogels: evaluation of $\mathrm{pH}$, ionic strength and temperature effect. Food Hydrocolloids, 48, 292-300.

Branco, C. Q. (2015). Production of nano-systems of whey protein by conventional and ohmic heating. MSc Thesis. University of Minho.

Cerqueira, M. A., Pinheiro, A. C., Silva, H. D., Ramos, P. E., Azevedo, M. A., FloresLópez, M. L., et al. (2014). Design of bio-nanosystems for oral delivery of functional compounds. Food Engineering Reviews, 6, 1-19.

Chen, L., Remondetto, G. E., \& Subirade, M. (2006). Food protein-based materials as nutraceutical delivery systems. Trends in Food Science \& Technology, 17(5), $272-283$.

Chen, L., \& Subirade, M. (2005). Chitosan/beta-lactoglobulin core-shell nanoparticles as nutraceutical carriers. Biomaterials, 26(30), 6041-6053.

Commission, E. (2011). Commission regulation (EU) on plastic materials and articles intended to come into contact with Food. In Official Journal of the European Union, 1-89. No 10/2011 of 14 January.

Diarrassouba, F. (2013). Interactions between $\beta$-lactoglobulin and nutraceutical ligands riboflavin, vitamin D3 and lysozyme. PhD Thesis. Université Laval.

Diarrassouba, F., Liang, L., Remondetto, G., \& Subirade, M. (2013). Nanocomplex formation between riboflavin and $\beta$-lactoglobulin: spectroscopic investigation and biological characterization. Food Research International, 52(2), 557-567.

Donato, L., Schmitt, C., Bovetto, L., \& Rouvet, M. (2009). Mechanism of formation of 
stable heat-induced $\beta$-lactoglobulin microgels. International Dairy Journal, 19(5), 295-306.

Fu, T. T., Abbott, U. R., \& Hatzos, C. (2002). Digestibility of food allergens and nonallergenic proteins in simulated gastric fluid and simulated intestinal fluid a comparative study. Journal of Agricultural and Food Chemistry, 50(24), 7154-7160.

Giroux, H. J., \& Britten, M. (2011). Encapsulation of hydrophobic aroma in whey protein nanoparticles. Journal of Microencapsulation, 28(5), 337-343.

Griffin, W. G., Griffin, M. C. A., Martin, S. R. \& Price, J. (1993). Molecular basis of thermal aggregation of bovine $\beta$-lactoglobulin A. Journal of the Chemical Society, Faraday Transactions, 89(18), 3395-3406.

Guerra, A., Etienne-Mesmin, L., Livrelli, V., Denis, S., Blanquet-Diot, S., \& Alric, M. (2012). Relevance and challenges in modeling human gastric and small intestinal digestion. Trends in Biotechnology, 30(11), 591-600.

Gunasekaran, S., Ko, S., \& Xiao, L. (2007). Use of whey proteins for encapsulation and controlled delivery applications. Journal of Food Engineering, 83(1), 31-40.

Horwitt, M. K., Harvey, C. C., Hills, O. W., \& Liebert, E. (1949). Correlation of urinary excretion of riboflavin with dietary intake and symptoms of ariboflavinosis. The Journal of Nutrition, 247-264.

Islam, M. A., Ekeberg, D., Rukke, E. O., \& Vegarud, G. E. (2015). Ex vivo digestion of milk from red chittagong cattle focusing proteolysis and lipolysis. Asian-Aus tralasian Journal of Animal Sciences, 28(4), 559-567.

Kolakowski, P. Dumay, E., \& Cheftel, J. C. (2001). Effects of high pressure and low temperature on $\beta$-lactoglobulin unfolding and aggregation. Food Hydrocolloids, 15(3), 215-232.

Kong, F., \& Singh, R. P. (2008). Disintegration of solid foods in human stomach. Journal of Food Science, 73(5), 67-80.

Liao, L., Zhao, M., Ren, J., Zhao, H., Cui, C., \& Hu, X. (2010). Effect of acetic acid deamidation-induced modification on functional and nutritional properties and conformation of wheat gluten. Journal of the Science of Food and Agriculture, 90(3), 409-417.

Madureira, A. R., Pereira, C. I., Gomes, A. M. P., Pintado, M. E., \& Malcata, F. X. (2007) Bovine whey proteins - overview on their main biological properties. Food Research International, 40, 1197-1211.

Mandalari, G., Adel-Patient, K., Barkholt, V., Baro, C., Bennett, L., Bublin, M., et al. (2009). In vitro digestibility of $\beta$-casein and $\beta$-lactoglobulin under simulated human gastric and duodenal conditions: a multi-laboratory evaluation. Regulatory Toxicology and Pharmacology, 55(3), 372-381.

McIntosh, G. H., Royle, P. J., Le Leu, R. K., Regester, G. O., Johnson, M. A. Grinsted, R. L., et al. (1998). Whey proteins as functional food ingredients? International Dairy Journal, 8, 425-434.

Moore, J., \& Cerasoli, E. (2010). Particle light scattering methods and applications. In John (Ed.), Encyclopedia of spectroscopy and spectrometry (2nd ed., pp. 2077-2088). Academic Press.

Peram, M. R., Loveday, S. M., Ye, A., \& Singh, H. (2013). In vitro gastric digestion of heat-induced aggregates of beta-lactoglobulin. Journal of Dairy Science, 96(1), 63-74.

Pereira, R. N., Souza, B. W., Cerqueira, M. A., Teixeira, J. A., \& Vicente, A. A. (2010). Effects of electric fields on protein unfolding and aggregation: influence on edible films formation. Biomacromolecules, 11, 2912-2918.

Picot, A., \& Lacroix, C. (2004). Encapsulation of bifidobacteria in whey protein-based microcapsules and survival in simulated gastrointestinal conditions and in yoghurt. International Dairy Journal, 14(6), 505-515.

Pinheiro, A. C. (2013). Development of nanostructures for application in food technology: Evaluation of their in vitro behaviour. PhD Thesis. Universidade do Minho.

Pinheiro, A. C., Bourbon, A. I., Cerqueira, M. A., Maricato, E., Nunes, C., Coimbra, M. A., et al. (2015). Chitosan/fucoidan multilayer nanocapsules as a vehicle for controlled release of bioactive compounds. Carbohydrate Polymers, $115,1-9$.

Pinheiro, A. C., Lad, M., Silva, H. D., Coimbra, M. A., Boland, M., \& Vicente, A. A (2013). Unravelling the behaviour of curcumin nanoemulsions during in vitro digestion: effect of the surface charge. Soft Matter, 9(11), 3147.

Powers, H. J. (2003). Riboflavin (vitamin B-2) and health. The American Journal of Clinical Nutrition, $77,1352-1360$.

Ramos, O. L., Pereira, R. N., Martins, A., Rodrigues, R., Fucinos, C., Teixeira, J. A., et al. (2015). Design of whey protein nanostructures for incorporation and release of nutraceutical compounds in food. Critical Reviews in Food Science and Nutrition,

Ramos, O. L., Pereira, R. N., Rodrigues, R., Teixeira, J. A., Vicente, A. A., \& Xavier Malcata, F. (2014). Physical effects upon whey protein aggregation for nanocoating production. Food Research International, 66, 344-355.

Ramos, O. L., Pereira, J. O., Silva, S. I., Amorim, M. M., Fernandes, J. C., Lopes-daSilva, J. A., et al. (2012). Effect of composition of commercial whey protein preparations upon gelation at various $\mathrm{pH}$ values. Food Research International, 48(2), 681-689.

Rodrigues, R. M., Martins, A. J., Ramos, O. L., Malcata, F. X., Teixeira, J. A., Vicente, A. A., et al. (2015). Influence of moderate electric fields on gelation of whey protein isolate. Food Hydrocolloids, 43, 329-339.

Sá, É. S., da Silva, P. S., Jost, C. L., \& Spinelli, A. (2015). Electrochemical sensor based on bismuth-film electrode for voltammetric studies on vitamin B2 (riboflavin). Sensors and Actuators B: Chemical, 209, 423-430.

Tavel, L., Moreau, C., Bouhallab, S., Li-Chan, E. C. Y., \& Guichard, E. (2010). Interactions between aroma compounds and $\beta$-lactoglobulin in the heat-induced molten globule state. Food Chemistry, 119(4), 1550-1556.

Thomson, A. B. R., Shaffer, E. A., \& Gonska, T. (2014). First principles of gastroenterology and hepatology in adults and children (Vol. 1). CAPstone.

Zimet, P., \& Livney, Y. D. (2009). Beta-lactoglobulin and its nanocomplexes with pectin as vehicles for $\omega-3$ polyunsaturated fatty acids. Food Hydrocolloids, 23(4), 1120-1126. 